\title{
ПСИХОЛОГИЯ И ДУХОВНОСТЬ - ДВЕ ВЕЩИ НЕСОВМЕСТНЫЕ?
}

\author{
Б.С. БРАТУСБ \\ ${ }^{a}$ Московский государственный университет имени М.В. Ломоносова, 119991, Россия, Москва, \\ Ленинские горы, Ә. 1
}

\begin{abstract}
Резюме
В статье рассмотрены место и роль духовности в построении психологического знания. Обычно эта тема не вызывает энтузиазма у современных психологов, которые целиком относят ее к областям религии и философии, не имеющим, по их мнению, прямого касательства к конкретным психологическим проблемам. Автор показывает, что речь идет о двух пересекающихся плоскостях: горизонтальной («как?», «для чего?») и вертикальной («ради чего?», «в чем смысл?»). Автор предлагает постулировать это взаимодействие как изначально присутствующее в деятельности человека. По сути, говорится о двух формах бытия - протяженной и не протяженной, материальной и духовной. Материальное при этом ждет одухотворения, а духовное - материализации. В обыденном сознании эта двойственность бытия много веков отражена в понятии души, в котором переплетены как сугубо чувственные моменты (душа страдает, ликует, гневается и др.), так и духовные воспарения, переходы в историю, культуру, религию. Психология как наука сосредоточена на горизонтальном измерении и исходит из него как главной и единственной предпосылки развития. Между тем психология имеет выраженный общегуманитарный компонент, а значит, согласно немецкой научной традиции, может быть отнесена к наукам о духе (Geisteswissenschaft). Речь, таким образом, идет об общем для формирования науки процессе - аксиоматизации того, что нельзя доказать, но из чего приходится исходить, чтобы построить предметную область. Психология вне аксиоматического признания двойственности бытия останется эпифеноменом, а не сущностным условием понимания развития и становления феномена человека.
\end{abstract}

Ключевые слова: философия, психология, религия, духовность, дух, душа, судьба, личность.

Статья посвящена теме духовности как возможному тренду современной психологии. Продолжать ли нам жить и безбедно здравствовать в психологии без понятий «душа» и «дух» или впустить этих бедных, изгнанных 150 лет назад родственников на пиршество психологической науки и практики? Эта тема обычно не вызывает никакого энтузиазма у коллег. Более того, как только в разговоре заходит речь о «нравственности», «духовности», «душе», обычно

По материалам доклада на панельной дискуссии «Духовность. Сексуальность. Цифра. Куда уводят тренды?», которая состоялась 2 июня 2019 г. на Санкт-Петербургском саммите психологов. 
меняется даже выражение лиц собеседников. Оно становится вежливо-скучным или скорбно-отчужденным, как на официальных похоронах, или кислым, словно речь идет о чем-то набившем оскомину. Случается и так, что с меня начинают требовать ответа за костры инквизиции, за промахи современной церковной администрации и т.п.

В любом случае на пути к обсуждению лежат застарелые бревна и сучья недоумений и отчуждения - как и зачем говорить о давно отринутых вещах? Моя скромная задача сейчас, не вдаваясь в подробности, хоть немного отодвинуть некоторые из этих сучьев и бревен, чтобы пусть не сегодня, а в дальнейшем приоткрыть путь к действительному обсуждению предмета, а не его многочисленных теней и ассоциаций. Предварительно это нужно сделать хотя бы в общих чертах, иллюстративно.

Начну с картинки. Представим военный парад, скажем, на Красной площади. Чеканным шагом идут колонны представителей всех родов войск, танки, артиллерия, ракеты. И я подумал по аналогии, почему бы нам не приурочить к нашему Петербургскому саммиту психологов еще и парад наличных психологических подразделений и техники. Представьте, что перед вашим величественным собранием прямо сейчас появляется колонна краснознаменного, медалей Л.С. Выготского и С.Л. Рубинштейна культурно-деятельностного подхода. Во главе колонны - Александр Григорьевич Асмолов. Вслед с портретами Б.Г. Ананьева, В.Н. Мясищего, Б.Д. Карвасарского, Л.М. Веккера движется колонна Санкт-Петербургского университета. Отдельный колонной идут представители психологии сознания во главе с Виктором Михайловичем Аллахвердовым и Виктором Федоровичем Петренко. В свете отраженной субъектности надситуативно пролетает эскадрилья во главе с Вадимом Артуровичем Петровским. На площадь ступает колонна психоаналитиков, которую ведет Михаил Михайлович Решетников. На подходе гештальтисты, бихевиористы, службы психологической помощи населению, представители позитивной психологии с неотразимыми улыбками, нестройными рядами приближаются благостные гуманистические психологи и др. А вот и техника: на открытых платформах с надписью ИМАТОН везут новейшие пособия, кресла и кушетки. Гвоздь парада - многомилионное психофизиологическое оборудование, установки залповой виртуальной имитации, идентичной натуральной. Парад завершит, наверное, колонна странноватых субъектов в потертых костюмах и сношенных башмаках. Это теоретики и методологи, продолжающие по ходу движения спорить и ссориться друг с другом...

Но вот закончился такой парад. Отгремели здравицы и аплодисменты. Но куда двинется это сборище? Какой общий тренд можем мы предложить им? Если вернуться к повестке данной дискуссии («Духовность. Сексуальность. Цифра. Куда уводят тренды?»), то надо поставить камень у распутья: направо пойдешь - оцифрован будешь; налево пойдешь - в многообразие чувственности попадешь; прямо пойдешь - духовность обретешь.

Но если вернуться к нашей картинке, образу, то, скорее всего, колонны минуют этот камень на распутье, зазывал на трибунах и страницах статей и разбредутся каждая по своим, оставленным на время домикам и хуторкам, 
зорко и ревностно поглядывая на других. Если представить себе некую местность, куда они все утекают, некое поселение этих хуторков под названием «Психология», то это поселение будет похоже на блоковский квартал поэтов:

За городом вырос пустынный квартал

На почве болотной и зыбкой.

Там жили поэты, - и каждый встречал

Другого надменной ульљкой.

Одно к одному. Надо лишь заменить слово «поэты» на слово «психологи» и картина будет вполне узнаваемой, вплоть до деталей - надменной улыбки в отношении других направлений и крайней зыбкости почвы наших построений.

И что же здесь способно объединить, какое общее направление можно предложить или выявить среди этих всех заборчиков, палисадничков, уязвленных самолюбий и погоней за грантами?

Но последуем за Александром Блоком. Словно бы отвечая на наш вопрос, весьма нелицеприятно описав до этого поэтов с их пьянством, увлечениями девичьми косами и облаками, Блок заключает следующее:

Нет, мой мильй читатель, мой критик слепой!

По крайности, есть у поэта

И косы, и тучки, и век золотой,

Тебе ж не доступно все это!..

ть будешь доволен собой и женой,

Своей конституцией куцой,

А вот у поэта - всемирньй запой,

И мало ему конституиий!

Пускай я умру под забором, как пес,

Пусть жизнь меня в землю втоптала -

Я верю: то Бог меня снегом занес,

То въюга меня целовала.

Объединение всей этой разномастности, действительное, а не искусственное, может быть осуществлено тем самым не по горизонтали, углам и нюансам движения, которых бесконечное количество в ту или иную сторону, а по вертикали, в подъеме на какой-то объединяющий и преобразующий всех уровень и высоту. Если хотите, это не направление хода развития, а направление взгляда на развитие.

Скажем, парад, смотр войск - это в конечном итоге демонстрация убойной силы и агрессии, кулак, поднесенный к носу врага, гордость, что мы можем разнести весь мир в щепу и посыпать сверху радиоактивной пылью. Парад психологического воинства оправдан в конечном итоге другим - интересом к человеку, его внутреннему миру, желанием помочь ему в перипетиях психической жизни. В идеале, в пределе - осуществить, явить деятельную любовь к этому предмету.

Можно соглашаться или не соглашаться с этим, но суть такой формы объединения, думаю, понятна. Оно не в привычной плоскости горизонтали, дорожных карт, вре́менных и временны́х перспектив, планов и пятилеток, а в 
плоскости вертикали, которая пронизывает каждый момент вне зависимости от того, имеет ли он продолжение в будущем или нет ${ }^{1}$.

Так вот, когда мы начинаем говорить о «духовности», это должно означать только то, не больше и не меньше, что мы переходим в иную, вертикальную плоскость, пронизывающую горизонталь. Пронизывающую явно или чаще неявно.

Если хотите, это связано в пределе с десантированием вечности на плоскость времени. Помните у Б. Пастернака: «Ты времени заложник у вечности в плену». С другой стороны, мы, поднимая глаза вверх, невольно сами изнутри ищем вечности, предуготованной нам, размечаем место для ее посадки в нашем внутреннем пространстве. 250 лет всем понятны и всех трогают слова Иммануила Канта: «Две вещи неизменно наполняют душу всегда новым и все более сильным удивлением и благоговением, чем чаще и продолжительнее мы размышляем о них, - это звездное небо надо мной и моральный закон во мне» (Кант, 1965, с. 499).

Нравственный закон изнутри подразумевает небо, а небо ищет воплощения и своего отражения во внутреннем нравственном законе. Вспомним хайдеггеровский экзистенциал «зова», который локализуется одновременно извне и внутри (Хайдеггер, 1996). Нужен тот, кто уже ждет и слышит. Поэтому, сместившись на полюс субъекта, не точнее ли говорить «Отзыв»: мы отзываемся на то, что нас отзывает, что распознается в нас, как «зов» (Братусь, 2019). Сама пеленгация сквозь все шумы, помехи, расстояния возможна потому, что посланная частота (волна послания) хоть в чем-то совпадает с уже имеющимся эталоном (диапазоном приемника, его настройкой), и в этом плане «отзыв» как готовность и предчувствие возникает едва ли не раньше самого «зова».

Итак, духовность не рядоположна поискам оцифровки, исследованиям сексуальности, психофизиологическим мозгокопаниям, когнитивистским построениям, поскольку относима к другой плоскости и модальности: не горизонтальной, а вертикальной, не движения, а присутствия или свидетельствования.

Давно ли человек являет собой это присутствие или свидетельство? Можно ответить достаточно твердо - изначала. Процитирую старого психолога: «Философия в своем развитии свято сохранила это первое открытие первобытного человека, его мысль о двойном бытии: материальном и духовном, тела и духа. Эта мысль и родила все многочисленные разновидности материализма и спиритуализма» (Рубинштейн, 2008, с. 296).

О том же, по сути, писал и Л.С. Выготский: идея души явилась «первой научной гипотезой древнего человека, огромным завоеванием мысли, которому

\footnotetext{
${ }^{1}$ Страницу и огонь, зерно и жернова, секиры острие и усеченныи волосБог сохраняет все; особенно - слова прощенья и любви, как собственный свой голос.
}

Иосиф Бродский 
мы сейчас обязаны существованием и рождением нашей науки» (Выготский, 1982, с. 429).

Последнее, однако, можно оспорить. Наша психологическая наука началась как раз с отвержения души и духа. Основной удар здесь пришелся, конечно, по понятию души, как связующего опосредствующего звена между материальным и духовным. Об этом писал И. Кант, и ту же мысль поэтически выразил Федор Тютчева: «О вещая душа моя, / О сердце, полное тревоги, - / O, как ты бьешься на пороге / Как бы двойного бытия... // Так ты - жилица двух миров...».

Душа как жилица, страдалица, свидетельница этой изначальной двумерности была в конце XIX в. сдана как входной билет в сферу научного знания, где, согласно еще предписанию Галилея, измеряемое надо измерить, а неизмеряемое сделать измеряемым. Но один из миров, в котором обитает эта жилица, состоит из прямо неизмеряемого. Воспользуемся иллюстрацией, на этот раз из Николая Гумилева:
Прекрасно в нас влюбленное вино
И добрый хлеб, что в печь для нас садится,
И женщина, которою дано,
Сперва измучившись, нам насладиться.
Но что нам делать с розовой зарей
Над холодеющими небесами,
Гое тишина и неземной покой,
Что делать нам с бессмертньми стихами?
Ни съесть, ни выпить, ни поцеловать...

Психология, вынув, потеряв душу, развела две сферы, и человек, по словам И. Бергмана (Бергман, 1969), обнаружил себя на теплой и грязной земле под пустым холодным небом. Туда же, в небеса, была закинута и душа, лишившись теплоты и земной печали, чтобы ничто не напоминало, не соединяло нас здесь, на земле, с горним миром.

Недавно на семинаре я спросил студентов третьего курса факультета психологии МГУ, какие у них возникают ассоциации с понятием «душа». После долгой и недоуменной паузы они сказали: «Это что-то связанное с религией», «Это не научное представление о психике», «Это что-то таинственное, непонятное» и т.п.

Как же мы обработали их нашим современным психологическим образованием, чтобы успеть за три года обучения вытеснить, затушевать весь тысячелетний опыт жизни души как постоянно ощущаемой повседневной реальности, с которой соотносимы наши мысли, чувства и дела!

Ведь сколько существует эпитетов и оттенков, понятных, казалось бы, любому и обращенных отнюдь не к религии и к горнему миру. Начнем с международного вопля о спасении жизни - «Спасите наши души!». Или призыв к состраданию и разделению боли, которому две тысячи лет: «Душа моя скорбит смертельно, - побудьте здесь, пободрствуйте со мной». А сколько разбросано параметров и оттенков: душа болит, страдает, помнит, забывает, ликует, 
поет, плачет, восстает, спит, просыпается, обретает покой или не находит покоя, съеживается, расправляется, негодует, рвется на части, уходит внутрь (иногда даже указывается куда: как ни странно, в пятки). Она может быть сытой, довольной, мягкой, твердой, железной, каменной, высокой, надменной, низкой, гордой, смиренной, серой, жестокой, яркой и т.д. и т.п. Ею можно любоваться, ее можно отвергать, раскрывать, ее можно разбить, разорить, в нее можно плюнуть, влезть (вовсе плохо, когда грязными руками, да и когда кошки скребут - мало приятного).

Подумайте только, какое обширное, яркое, объемное поле, столько многообразных феноменов, оттенков, которые коммуницируют друг с другом, составляют некую целостность, непосредственную отнесенность к тому живому и трепетному образованию, которое веками обозначалось как душа. Ведь именно «душа», а не психика с радости воспаряет, а со страха холодеет и уходит в пятки. И люди живут вместе, если им очень повезет, «душа в душу», а не «психика в психику». И мечтают они о душевной, а вовсе не о психической атмосфере у себя дома и на работе.

Поэтому если говорить о возможном общем тренде или направлении, то это возвращение в оборот психологии понятий «душа» и «дух» как изначально присутствующих и действующих, без которых мы, по остроумному выражению В.И. Слободчикова, продолжим изучение «психологии психики», но не «психологии человека» (Слободчиков, Исаев, 2013).

Важно отметить при этом, что духовность не обязательно сводится только к религиозному аспекту. Речь, как мы видели, об области предельных смыслов или смыслов, соотносящихся с предельными, нематериальными основами бытия - то, что «ни съесть, ни выпить, ни поцеловать». В этом плане человек неизменен. И нынешняя погоня за адаптацией к изменяющемуся миру опасна в своей посылке, ибо не человек для бесконечного приспособления к миру, а мир для служения человеку. Но в любом варианте - и светском, и религиозном - духовное через душу соединено с психическим, определяя судьбу и драму человеческой жизни, ее наполненность, свершенность или пустоту, промах мимо себя.

У наших академических учителей-немцев есть по этому поводу два отдельных понятия, определяющих духовность. У нас только одно, что порождает недоразумения. В немецком языке geistig обозначает светское, интеллектуальное или, по Канту, умопостигаемое понимание духовности. И geistlich - духовность в религиозном плане. В обоих случаях корень geist - дух, ум. И, что тоже крайне важно, гуманитарные науки обозначены как Geisteswissenschaften, т.е. науки о духе. И это глубоко верно: история, например, не просто про деятельность царей и генеральных секретарей, не про одну политику, опрокинутую в прошлое, но, в конечном устремлении, про смысл и дух истории. Но давайте тогда дерзнем и обозначим и психологию не просто как науку о явлениях, законах, корреляциях, манипуляциях, а о смысле и роли психики - восприятия, памяти, сознания, личности - всего, что мы изучаем, в становлении человека, его мира, назначения и судьбы. 
Итак, поиск предельных ответов на вопросы «в чем смысл?», «ради чего?» присущ каждому человеку, составляя вертикаль и духовное измерение его развития. Научная психология стремится ответить на вопросы «как?» и «для чего?», что составляет по преимуществу «горизонталь». Их сопряжение (при всей реальной сложности) более чем необходимо - оно неизбежно, ибо реальное движение жизни подразумевает, изнутри требует, жаждет осознания ее смысла, а смысл подразумевает реализацию, т.е. осуществление в конкретном времени и пространстве. Психологу это надо знать отнюдь не из морализаторских соображений, а потому что это главная характеристика и задача личности, показатель ее цельности или, напротив, раскола, трещины, ущерба (Братусь, 2019). Собственно, любая психотерапия, шире - психологическая помощь направлена на ликвидацию какого-то вида раскола, могущего возникнуть на самых разных уровнях, начиная с обыденного и житейского. А.Н. Леонтьев в своих лекциях не раз повторял слова, сказанные ему сельским конюхом в Великую Отечественную войну: «Если лошадь устала, не нахлестывай ее, а подними ей повыше морду, чтобы она увидела деревню вдалеке и заспешила к дому» (Леонтьев, 1977). Вопрос в том, к какому дому, к какому граду мы поднимаем «психологическую морду». Остальное, не умаляя значимости профессионального образования и мастерства, - приложится.

\section{Литература}

Бергман, И. (1969). Статьи, рецензии, сценарии, интервью. М.: Искусство.

Братусь, Б. С. (2019). Аномалии личности. Психологический подход (2-е изд.). М.: Наука.

Выготский, Л. С. (1982). Вопросы теории и истории психологии. В кн. Л. С. Выготский, Собрание сочинений (т. 1). М.: Педагогика.

Кант, И. (1965). Сочинения (т. 4). М.: Мысль.

Леонтьев, А. Н. (1977). Деятельность. Сознание. Личность. М.: Политиздат.

Рубинштейн, М. М. (2008). О смысле жизни. Труды по философии ценности, теории образования и университетскому вопросу (т. 1). М.: Территория будущего.

Слободчиков, В. И., Исаев, Е. И. (2013). Психология человека. Введение в психологию субъективности (2-е изд.). М.: Изд-во Православного Свято-Тихоновского гуманитарного университета.

Хайдеггер, М. (1996). Бытие и время. М.: Республика.

Братусь Борис Сергеевич - профессор, факультет психологии, МГУ им. М.В. Ломоносова, доктор психологических наук, профессор, член-корреспондент РАО.

Сфера научных интересов: патопсихология, психология личности, христианская психология, философия психологии.

Контакты: kop-msu@mail.ru 


\title{
Are Psychology and Spirituality Incompatible?
}

\author{
B.S. Bratus ${ }^{\mathrm{a}}$ \\ ${ }^{a}$ Lomonosov Moscow State University, 1 Leninskie Gory, Moscow, 119991, Russian Federation
}

\begin{abstract}
The article examines the place and role of spirituality in the formation of psychological knowledge. Usually this topic does not arouse enthusiasm among modern psychologists. They attribute it entirely to the area of religion and philosophy, which, according to their views, has no direct relation to specific psychological problems. The author demonstrates that the discussion focuses on two intersecting levels: horizontal ("how?", "why?") and vertical ("what for?", "what is the point?"). The author proposes to postulate this interaction as something that initially exists in human activity. In fact, it is about two types of being - extensive and non-extensive, material and spiritual, where the material type is expecting to be spiritualized, while the spiritual - to be materialized. In the mundane consciousness, this duality of being has been reflected for many centuries in the concept of the soul, in which purely sensual moments (the soul suffers, exults, becomes angry, etc.), as well as spiritual fervors, transitions to history, culture, and religion have been intertwined. Psychology as a science is focused on the horizontal dimension, and proceeds from it as the main and only prerequisite for development. Meanwhile, psychology has a pronounced general humanitarian component, which means, according to German scientific tradition, that it can be attributed to the sciences of the spirit (Geisteswissenschaft). Thus, we are talking about a process that is common in the formation of science - the axiomatization of something that cannot be proved, but from which it is necessary to proceed in order to construct the subject area. Each science has a system of such axioms. Without the axiomatic recognition of the duality of being, Psychology will remain an epiphenomenon, but not the essential condition for understanding the development and formation of the human phenomenon.
\end{abstract}

Keywords: philosophy, psychology, religion, spirituality, spirit, soul, fate, personality.

\section{References}

Bergman, I. (1969). Stat'i, retsenzii, stsenarii, interv'yu [Articles, reviews, scripts, interviews]. Moscow: Iskusstvo. (in Russian)

Bratus, B. S. (2019). Anomalii lichnosti. Psikhologicheskii podkhod [Anomalies of personality. The psychological approach] (2nd ed.). Moscow: Nauka. (in Russian)

Heidegger, M. (1996). Bytie i vremya [Being and time]. Moscow: Respublika. (in Russian)

Kant, I. (1965). Sochineniya [Writings] (Vol. 4). Moscow: Mysl'. (in Russian)

Leontiev, A. N. (1977). Deyatel'nost'. Soznanie. Lichnost' [Activity. Consciousness. Personality]. Moscow: Politizdat. (in Russian)

Rubinstein, M. M. (2008). O smysle zhizni. Trudy po filosofii tsennosti, teorii obrazovaniya i universitetskoти vорrosu [On the meaning of life. Proceedings on the philosophy of value, theory of education, and the university question] (Vol. 1). Moscow: Territoriya budushchego. (in Russian) 
Slobodchikov, V. I., \& Isaev, E. I. (2013). Psikhologiya cheloveka. Vvedenie v psikhologiyu sub"ektivnosti [Human psychology: An introduction to the psychology of subjectivity] (2nd ed.). Moscow: Izdatelstvo Pravoslavnogo Svyato-Tikhonovskogo gumanitarnogo universiteta. (in Russian)

Vygotsky, L. S. (1982). Voprosy teorii $i$ istorii psikhologii [Questions of theory and history of psychology]. In L. S. Vygotskiy, Sobranie sochinenii [Collected works] (Vol. 1, p. 488). Moscow: Pedagogika. (in Russian)

Zinchenko, V. P. (2016). Filosofskoe nasledie [Philosophical heritage]. Moscow: Tsentr gumanitarnykh initsiativ. (in Russian)

Boris S. Bratus - professor, Department of Psychology, Lomonosov Moscow State University, D.Sc., professor, Corresponding Member of the Russian Academy of Education.

Researh area: pathopsychology, personality psychology, Christian psychology, philosophy of psychology.

E-mail: kop-msu@mail.ru 